\title{
INFLUENCIA DO PLASMA DE PERÓXIDO DE HIDROGÊNIO NA MOLHABILIDADE DA SUPERFÍCIE DE MEMBRANAS DE POLI(L-ÁCIDO LÁTICO)
}

\author{
C. R. MORAES ${ }^{1}$, M. A. T. DUARTE 2 , I. MACHADO ${ }^{3}$ e V. L. SOETHE $^{4}$ \\ ${ }^{1}$ Universidade Instituto Superior Tupy, Bacharelado em Engenharia Química \\ ${ }^{2}$ Universidade Instituto Superior Tupy, Mestrado em Engenharia Mecânica \\ ${ }^{3}$ Universidade Instituto Superior Tupy, Mestrado em Engenharia Mecânica \\ ${ }^{4}$ Universidade Federal de Santa Catarina, Centro da Engenharia da Mobilidade \\ E-mail para contato: carolinerettore@gmail.com
}

RESUMO - O PLLA poli (ácido L-lático) apresenta propriedades mecânicas satisfatórias como dispositivo biomédico, porém suas características hidrofóbicas tornam-no de difícil interação com as células. Assim, o objetivo geral deste trabalho foi avaliar a influência do tratamento de plasma de peróxido de hidrogênio na molhabilidade das superfícies das membranas de PLLA. As membranas obtidas por evaporação de solventes foram expostas ao plasma de $\mathrm{H}_{2} \mathrm{O}_{2}$ em diferentes tempos ( 1 a 5 minutos). Para verificar a influência do plasma realizou-se Microscopia Eletrônica de Varredura (MEV) e Ângulo de Contato. Através do MEV observaram-se modificações na superfície as mesmas tornaramse irregulares e com morfologias diferenciadas, e através do ângulo de contato pode-se notar que, no primeiro minuto de tratamento, a amostra já apresentava caráter hidrofílico. Através dos ensaios percebe-se a influência do plasma de $\mathrm{H}_{2} \mathrm{O}_{2}$ sobre a superfície da membrana de PLLA tornando hidrofílica, o que sugere uma maior interação célula/biomaterial.

\section{INTRODUÇÃO}

Durante décadas os biomateriais desempenharam um importante papel no controle e tratamento de doenças, possibilitando avanços na área da saúde, devido, principalmente a variedade de aplicações que apresentam, (Bazaka et al.,2006). Atualmente implantes temporários, confeccionados de polímeros ganharam importância crescente na área médica, por possuírem características favoráveis, como propriedades mecânicas e biocompatibilidade, (Zhang et al., 2006). Segundo Ferreira et al. (2008), a biocompatibilidade é um dos requisitos fundamentais para o perfeito desempenho dos biomateriais no organismo, que inclui características físicas, mecânicas, biológicas e morfológicas, evitando efeitos indesejáveis ao organismo no qual estão implantados.

O Poli (ácido lático) e seus copolímeros são polímeros atraentes para aplicações biomédicas, devido às suas boas propriedades mecânicas, processabilidade, biocompatibilidade e biodegradabilidade . Eles são fabricados a partir de fontes renováveis, que não são tóxicas para seres humanos e ao ambiente. Este polímero pertence a classe de poli ( $\alpha$-hidróxi ácidos) que constituem uma classe de poliésteres, um polímero semicristalino, com temperatura de transição vítrea em torno de $57{ }^{\circ} \mathrm{C}$ e ponto de fusão entre $174-184{ }^{\circ} \mathrm{C}$ e 
uma cristalinidade por volta de $70 \%$. Possui excelentes propriedades mecânicas, com módulo de elasticidade e resistência à tração na faixa de 3,2 a 3,7 GPa e 55 a $60 \mathrm{MPa}$ respectivamente, (Duarte, 2009). No entanto, a falta de grupos funcionais necessários para promover a fixação das células limita a sua utilização. Apesar do polímero, apresentar propriedades mecânicas satisfatórias para aplicação como dispositivo médico, suas características hidrofóbicas, tornaos de difícil interação com as células. Sendo assim, a modificação da superfície deste polímero é importante quando há necessidade de interação com os componentes fisiológicos, (Chu et al., 2006).

A técnica do plasma a baixa pressão e temperatura vêm sendo proposta para modificar as propriedades superficiais de materiais biopoliméricos, tais como molhabilidade, biocompatibilidade, permeabilidade, para adaptá-los as aplicações desejáveis preservando as propriedades já existentes do material. Quando uma substância polimérica é inserida no meio, diferentes efeitos podem resultar da interação plasma-superfície. Um dos principais efeitos é a interação química de espécies ativas do plasma com as moléculas da superfície do polímero, gerando novos grupos funcionais, mostrados em trabalho anteriores (Macêdo et al.,2011 e Chu et al., 2006). Para Macêdo et al. (2011), além da modificação da superfície dos biomateriais por plasma ser um método econômico e eficiente, cabe ressaltar que técnicas de tratamento utilizando plasma como meios energéticos permitem a obtenção de amostras em um ambiente limpo, a baixa pressão, ideal para tratamento de biomateriais, sendo ainda um processo que atende os requisitos ambientais de emissão nula de resíduos, resultando na aplicação, cada vez mais evidenciada, desta técnica na área biomédica. O plasma é considerado o quarto estado da matéria sendo composto por átomos, moléculas, íons e radicais altamente excitados, sendo obtidos por gases em estados energéticos por meio de rádio frequência, microondas e descargas de elétrons. Tais características do plasma permitem a obtenção de superfícies com funcionalidades específicas, uma vez que possibilitam a modificação dos materiais tratados, fornecendo-lhes as propriedades superficiais desejadas, (Bazaka et al., 2011). A grande vantagem desta técnica é a capacidade de modificar a superfície tornando-a mais biocompatível ou mimetizando melhor o tecido sem alterar suas propriedades, (Macêdo et al.,2011).

Sendo assim, o objetivo geral do presente trabalho é avaliar a influência tratamento de plasma de peróxido de hidrogênio na molhabilidade das superfícies das membranas de PLLA.

\section{MATERIAIS E MÉTODOS}

\subsection{Materiais}

O polímero Poli (L-Ácido Lático) utilizado para obtenção da membrana foi sintetizado nos laboratórios da PUC/Sorocaba com massa molar média de $260000 \mathrm{~g} / \mathrm{mol}$.

\subsection{Obtenção da Membrana de PLLA}

As membranas de PLLA foram obtidas por evaporação de solvente a temperatura ambiente. O PLLA foi dissolvido em clorofórmio P.A. obtendo-se soluções $10 \%(\mathrm{~m} / \mathrm{m})$, e mantido em agitador magnético por 24 horas, até completa homogeneização. As soluções foram colocadas em uma banheira ultra-sônica digital por 25 minutos a $35^{\circ} \mathrm{C}$ para retiradas 
de bolhas proveniente do processo da agitação. Após este processo verteu-se a solução em um molde de vidro $(50 \times 50 \times 5 \mathrm{~mm})$ e foram deixadas em uma câmera saturada com clorofórmio para evaporação do solvente por 24 horas. Os filmes foram secos em uma estufa ao vácuo durante 24 horas e armazenados no dessecador. Para estudo da influência da degradação hidrolítica, serão estudadas membranas modificadas por plasma de $\mathrm{H}_{2} \mathrm{O}_{2}$ comparadas com membranas sem tratamento.

\subsection{Tratamento por plasma}

Membranas de PLLA foram tratadas por plasma de peróxido de hidrogênio (50\%) PA da marca FMAIA, fazendo uso de um equipamento de plasma do Laboratório de Plasmas do Departamento de Física da Universidade do Estado de Santa Catarina - UDESC. O sistema consiste de uma fonte de corrente contínua, sistema de vácuo $\left(1,5 \times 10-^{1}\right.$ torr $)$, a voltagem de saída máxima de $400 \mathrm{~V}$ e está acoplada capacitivamente ao reator. O reator consiste de cilindro de aço inox, com dois flanges em sua latera. Durante o tratamento das membranas de PLLA foram mantidas constantes a pressão do gás de trabalho e a voltagem da fonte de potência, sendo modificado o tempo de exposição ao plasma, onde foram utilizados os tempos $0,1,2,3,4$ e 5 minutos, e corrente e temperatura sem variação, $0,2 \mathrm{~A}$ e $27^{\circ} \mathrm{C}$ respectivamente.

\subsection{Análise por microscopia eletrônica de varredura (MEV)}

As amostras das superfícies das membranas foram metalizadas com ouro (SputterCoater BAL-TEC SCD 050) e analisadas em um microscópio eletrônico de varredura (JEOL JXA 860) operado a 10kV. O ensaio foi realizado na UNICAMP.

\section{5 Ângulo de contato}

As análises foram realizadas na UDESC (Universidade do Estado de Santa Catarina), onde as medidas de ângulo de contato foram obtidas empregando-se o goniômetro (RaméHart 100-00) operando em temperatura ambiente. Os ângulos de contato do lado direito e esquerdo da gota foram calculados automaticamente, por meio de software RHI 2001 Imaging Software instalado em um computador, acoplado ao equipamento. Medidas de ângulo de contato também foram empregadas para avaliação da energia de superfície das amostras. Isto foi feito medindo-se o ângulo $(\theta)$ para a glicerina.

\section{RESULTADOS E DISCUSSÕES}

\section{1. Microscopia eletrônica de varredura}

As morfologias das membranas com e sem tratamento por peróxido de hidrogênio foram analisadas por MEV. Na Figura 1 observa-se a superfície superior das membranas de PLLA, onde a Figura 1(a) representa a micrografia da membrana sem tratamento; as Figuras 1 b, c, d, e e f retratam as amostra tratadas por 1,2,3,4 e 5 minutos de tratamento, respectivamente. 
Figura 1 - Micrografias das amostras de membranas de PLLA

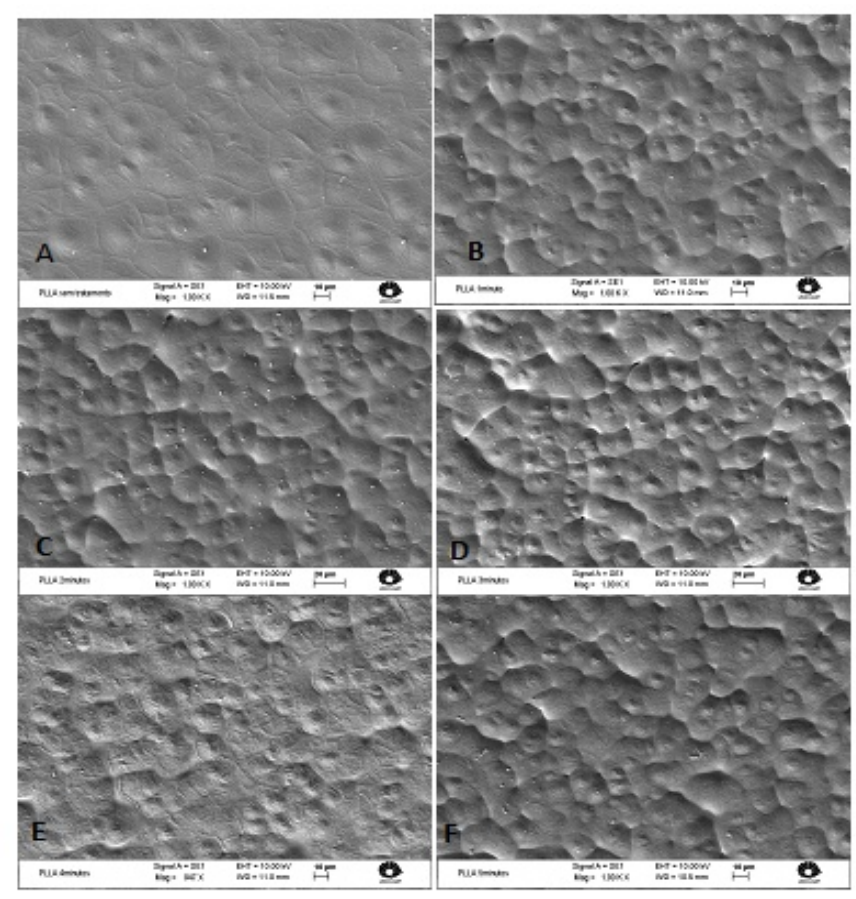

Através das micrografias obtidas por MEV ilustradas na Figura 1(a), observa-se que a membrana de PLLA sem tratamento por plasma apresenta uma morfologia densa com pequenas ondulações caracterizando uma estrutura pouco rugosa. Nas imagens seguintes nota-se que já na amostra tratada por plasma por tempo de 1 minuto, apresentou modificação significativa na morfologia da superfície do polímero, mostrando que o plasma começa a ter efeito sobre a superfície da membrana, apresentando características de estruturas em gomos, assemelhando surgimento de uma alteração na rugosidade do material. Tais características observadas também nas Figuras 1(c) e 1(d), das membranas com 2 e 3 minutos de exposição ao plasma. De acordo a micrografia ilustrada nas Figuras 1(e) e 1(f) o tratamento por plasma acima de três minutos de exposição da amostra torna-se ineficiente na alteração da morfologia da superfície das membranas, visto que, amostras tratadas em tempos de 4 e 5 minutos não observa-se modificações significativas na superfície da amostra, quando comparadas com a amostra exposta ao plasma de $3 \mathrm{~min}$. Conforme análise das imagens da Figura 1 verifica-se que o tratamento por plasma é capaz de alterar a morfologia da superfície da membrana exposta ao mesmo. Estudos realizados por Luchesi (2006) apresentou as modificações feitas por plasma no copolímero de Poli (hidroxibutirato-co-hidroxivalerato) (PHBV), observou-se através do ensaio de MEV que as modificações da superfície proporcionaram melhor adesão, espalhamento e proliferação celular.

\section{2. Ângulo de contato}

Conforme Wan et al. (2003) um dos parâmetros importantes para a biocompatibilidade de um biomaterial é a hidrofilicidade da superfície, que bem balanceada contribui com a adesão celular. A medição do ângulo de contato nos permite mensurar a molhabilidade do material analisado. Lim et.al. (2004) assumiu que valores de $\theta \leq 65^{\circ}$ e tensão de adesão de 
água $(\tau)$ igual a 30 dina. $\mathrm{cm}^{-1}$ são critérios utilizados para determinar a hidrofilicidade na superfície das membranas. Os resultados obtidos no ensaio de ângulo de contato das membranas de PLLA tratadas por plasma em diferentes tempos e sem tratamento estão demonstrados na Tabela 1 .

Tabela 1 - Ângulo de contato e energia de superfície das membranas de PLLA.

\begin{tabular}{|c|c|c|c|c|c|c|}
\hline \multirow[t]{2}{*}{ Amostra } & \multicolumn{2}{|c|}{ Ângulo de Contato $(\theta)$} & \multirow[t]{2}{*}{$\begin{array}{c}\begin{array}{c}\text { Tensão } \\
\text { de } \\
\text { adesão }\end{array} \\
\text { de água } \\
\text { dina.cm }{ }^{-1}\end{array}$} & \multicolumn{3}{|c|}{ Energia de Superfície $\left(\mathrm{mJ} / \mathrm{m}^{2}\right.$} \\
\hline & $\theta \mathrm{H}_{2} \mathrm{O}$ & $\theta \mathrm{C}_{3} \mathrm{H}_{5}(\mathrm{OH})_{3}$ & & $Y_{s}$ & $\mathrm{Ys}_{\mathrm{s}}^{\mathrm{p}}$ & $Y_{s}{ }^{d}$ \\
\hline PLLA 0 & 92,69 & 79,00 & $-3,41$ & 28,01 & 7,99 & 20,01 \\
\hline PLLA $1 \mathrm{~min}$ & 55,83 & 48,30 & 40,88 & 47,00 & 29,79 & 17,21 \\
\hline PLLA 2min & 48,34 & 48,26 & 48,39 & 52,21 & 39,36 & 12,84 \\
\hline PLLA 3min & 39,53 & 45,20 & 56,15 & 59,62 & 48,43 & 11,20 \\
\hline PLLA 4min & 42,65 & 61,45 & 53,54 & 71,07 & 68,41 & 2,66 \\
\hline PLLA 5min & 55,31 & 30,65 & 41,43 & 55,54 & 21,93 & 33,62 \\
\hline
\end{tabular}

$Y_{s}=$ energia de superfície, $Y_{s}{ }^{p}=$ componente polar, $Y_{s}{ }^{d}=$ componente dispersiva $\tau=$ tensão de adesão da água.

De acordo com a Tabela 1, observa-se que as superfícies da membrana de PLLA que não foram expostas ao tratamento por plasma de peróxido de hidrogênio possuem característica hidrofóbica. Conforme os valores encontrados na Tabela 1, as amostras que tiveram tratamento com plasma a partir de um minuto de exposição apresentam alterações significativas no ângulo de contato. Assim, pode-se afirmar que o tratamento com plasma contribuiu para uma superfície hidrofílica, sendo demonstrado através da diminuição do ângulo de contato, e através da tensão de adesão da água e pelo aumento expressivo da energia da superfície. Pode-se observar nos resultados obtido na Tabela 1 que, a amostra exposta ao tratamento de superfície pelo tempo de 3 minutos foi a que apresentou maior redução no ângulo de contato e aumento da energia de superfície. De acordo com os resultados obtidos, o tratamento de superfície por plasma de peróxido de hidrogênio alterou a propriedade hidrofóbica da membrana de PLLA para hidrofílica.

\section{CONCLUSÃO}

Baseado nos resultados apresentados verifica-se que a influência do tratamento de plasma com atmosfera de peróxido de hidrogênio contribui para o aumento da hidrofilicidade de membranas de poli (ácido láctico). Os resultados obtidos pelo ensaio de microscopia eletrônica de varredura (MEV) expõem a alteração de morfologia da superfície das membranas de PLLA que foram expostas ao tratamento por plasma. Nessa análise se observou que amostra tratada pelo tempo de três minutos se apresentou mais eficiente quando comparado com as demais, a amostra em questão mostrou característica mais intensa de alteração de morfológica. Com os dados encontrados no ensaio do ângulo de contato é possível verificar que a técnica de modificação de superfície por plasma é eficiente devido, aos valores significativos encontrados como a redução do ângulo e contato e o aumento da energia de superfície. Esses fatores, de acordo com a teoria, caracterizam o material como 


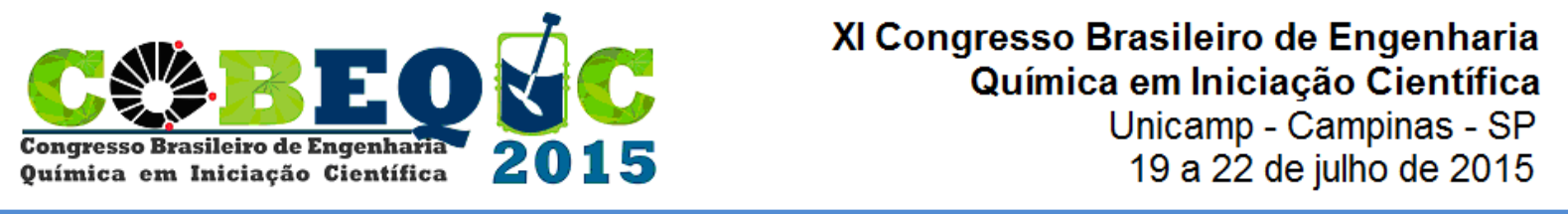

hidrofílico o qual apresentara melhor desempenho em aplicações que exigem maior grau de adesão celular.

Sendo assim, com o presente estudo foi possível a confirmação da viabilidade do tratamento por plasma de peróxido de hidrogênio no polímero PLLA para a obtenção de um maior espectro de propriedades. Além de possuir vantagens como, ser ambientalmente correto e ao mesmo tempo esterilizar o material foi possível a funcionalização da superfície do polímero. Por meio de testes de ângulo de contato onde a membrana demonstrou aumento na hidrofilicidade, acredita-se que o material terá uma melhora na adesão celular e consequentemente na aplicabilidade deste como dispositivo médico.

\section{REFERÊNCIAS}

BAZAKA, K.; JACOB, M. V.; CRAWFORD, R. J.; IVANOVA, E. Plasma-Assisted Surface Modification of Organic Biopolymers to Prevent Bacterial Attachment. Acta Biomaterialia, v. 7, p. 2015-2018, maio 2011.

CHU, P. K.; CHEN, J.Y.; WANG, L. P.; HUANG, N. Plasma Surface Treatment of Artificial Orthopedic and Cardiovascular Biomaterials. Surface \& Coatings Technology, v. 201, p. 5601-5606, agosto, 2006.

DUARTE, M. A. T. Influências das Concentrações do PCL-T em Membranas de PLDLA. Estudo in vitro $\boldsymbol{e}$ in vivo. 2009, 6p. Tese ( Doutorado em Engenharia Mecânica) Universidade Estadual de Campinas, Campinas.

FERREIRA, B. M. P.; PINHEIRO, L. P. M.; NASCENTE, P. A. P.; FERREIRA, M. J.; DUEK, E. A. R.; plasma surfasse treatments of poly(L-lactic acid) (PLLA) and poly (hydroybutyrate-co-hydroxyvalerato) (PHBV). Materials Science and Engineering, Sorocaba, 2008.

ZHANG, N. KOTAKI, M. OKUBAYASHI, S. SUKIGARA. S. Effect of electron beam irradiation on the structure and proprieties of eletrospun PLLA and PLLA/PDLA blend nanofibers. Acta Biomaterialia, v.6, p.123-129, janeiro, 2010.

LIM J. Y.; LIU X.; VOGLER E. A.; DONAHUE H.J. Systematic Variation In Osteoblast Adhesion And Phenotype With Substratum Surface Characteristics. Journal Biomed Matter $\operatorname{Res} \boldsymbol{A}, 68$, p.504-512, 2004.

LUCHESI, C.; Cultura de células vero sobre membranas de poli(hidroxibutirato-cohidroxivalerato) (phbv) tratadas por plasma gasoso. 71 - Universidade Estadual De Campinas, Campinas, 2006.

MACEDO, M.; MACÊDO, H. R. A.; BARBOSA, J. C. P.; GUERRA NETO, C. L. B.; PEREIRA, M. R.; ALVES JUNIOR, C. O uso do plasma de nitrogênio para modificação superficial em membranas de quitosana. Revista Brasileira de Inovação Tecnológica em Saúde, 2011.

WAN, Y., YANG, J., YANG, J. Cell Adhesion On Gaseous Plasma Modified Poly- (LLactide) Surface Under Shear Stress Field. Biomaterials, v. 24, n. 21, p. 3757-3764, 2003. 